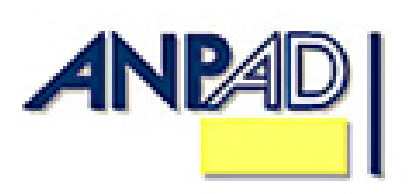

Available online at http://www.anpad.org.br/bar

\title{
Implementing Strategies in Complex Systems: Lessons from Brazilian Hospitals
}

\author{
Victor Meyer Junior * \\ E-mail address: vmeyer@matrix.com.br \\ Pontifícia Universidade Católica do Paraná - PUCPR and De Paul University - USA \\ Curitiba, PR, Brazil. \\ Lucilaine Pascucci \\ E-mail address: lucilaine.pascucci@gmail.com \\ Universidade Positivo - UP \\ Curitiba, PR, Brazil. \\ J. Patrick Murphy \\ E-mail address: jpmurphy@ depaul.edu \\ De Paul University \\ Chicago, Illinois, USA.
}

* Corresponding author: Victor Meyer Junior Rua Imaculada Conceição, 1155, Centro de Ciências Sociais Aplicadas, Prado Velho, Curitiba, PR, 80215-901, Brazil.

Copyright (C) 2012 Brazilian Administration Review. All rights reserved, including rights for translation. Parts of this work may be quoted without prior knowledge on the condition that the source is identified. 


\begin{abstract}
Hospitals, as social organizations, are seen as complex, surprising, ambiguous and paradoxical. The theoretical foundation finds its roots in organizational complexity, strategic management characterized by strategy implementation, and sensemaking especially in the context of complex adaptive systems. Managers frequently neglect elements of complexity when they develop models and implement management practices. The purpose of this study is to analyze the implementation of strategies in complex organizations. The focus of the study is two Brazilian nonprofit hospitals. This is a comparative, qualitative case study. Data were gathered from three main sources: interviews, non-participant observation, and documents. Two important aspects of the strategic approach are discussed: first, the implementation of strategies, and second, the influence of ambiguity, unpredictability and uncertainty in the way strategies are implemented. The analysis indicated that the implementation of strategies in the hospitals has to do with the practices and processes that are adopted (how) and the practitioners (strategists) involved (who). The findings reinforce the importance played by the strategizing process in the implementation of strategies. The findings also highlight that strategic practices are adopted in parallel with the formal planning and are characterized by informality.
\end{abstract}

Key words: implementation of strategies; complex systems; strategic practices. 


\section{Introduction}

Social organizations are difficult to understand; they are complex, surprising, ambiguous and paradoxical. Organizational scholars such as Etzioni (1964), Perrow (1986), Bolman and Deal (2003) and Scott (2008) suggest that managers frequently overlook these distinctive characteristics when developing and implementing management models and practices. Understanding the special characteristics and complexities of social or nonprofit organizations is necessary in order to develop suitable management models or approaches. Managers often import models from other sectors, with dubious benefits and results.

To Johnson, Scholes and Whittington (2007, p. 12) strategic management "includes understanding the strategic position of an organization, strategic choices for the future and managing strategy in action". Strategic management has spread into institutions as varied as corporations, governments, social organizations, museums, universities and hospitals. Scholars have questioned its effectiveness because strategic management relies on a form of management based on rational assumptions not usually found in most organizations and because it is a process requiring significant outlays of time and resources. Furthermore, the implementation of strategies is even more important in this approach to management.

This study analyzes the implementation of strategies in complex systems by investigating the practices adopted by hospital management to reduce the gap between management intention and management action. The study centers on two large, Brazilian nonprofit hospitals with national reputations in their specialty fields. Specifically this study asks four questions: (a) How is strategizing done?; (b) What practices are developed related to the implementation of strategies?; (c) Who does the strategizing?; (d) What is common or different in the implementation of strategies in the two hospitals? To answer these questions, we examine the strategic process itself. Who are the practitioners that design and create the strategy? What strategic practices do organizations develop to account for the various processes and divergent results from strategic management at these hospitals?

The discussion flows from two important aspects of strategic management in organizations. The first is the implementation of strategies, a particularly perplexing challenge to managers. Secondly, organizations are complex systems whose ambiguity, unpredictability, and uncertainty greatly influence the way strategies emerge and are then implemented. We also highlight opportunities for research and the challenges adaptive complex systems pose to the field of organizational strategy.

\section{The relevance of implementing strategies}

Strategy implementation is defined as the process of transforming intentions into actions. The dichotomy between intentions and actions has been central to the study of strategic management in organizations (Hrebiniak \& Joyce, 2001; Mintzberg, 1994; Pfeffer \& Sutton, 2006). Nevertheless, a full discussion of strategy implementation has been missing or undervalued in the considerable literature on strategic management.

Having a strategy is important, but carrying it out is essential (Murphy, 2007). Strategy formulation and organizational performance have been the subject of much study, but most of the time the problem is not what to do, but how to do it (Pfeffer \& Sutton, 2006). People usually spend most of their time dedicated to analysis and the elaboration of scenarios as well as making projections of ideal strategies. But the most important phase, putting it into practice, is almost always ignored.

In general, strategy formulation disregards factors otherwise considered fundamental to implementation. For example human beings feel, interpret, and base their actions on rationality that is, above all, limited (Simon, 1997). The influence of Weick's $(1979,2009)$ notion of sensemaking in the decision making process has also been neglected. Yet strategy plays itself out in action that is often 
greatly influenced by interpretation. Divergent interests and political agents make strategy implementation ripe for renegotiation - something that often results in changes to prior plans.

Enacted strategies are rarely the result of a single person working alone. On the contrary, they are developed by a group of people at various levels working together in a most complex process (Johnson, Langley, Melin, \& Whittington, 2007). Formulation and implementation, then, are the results of a collective process in which thinking and acting go together. Moreover, the thinking does not necessarily end before the action starts (Chaffee, 1985; Mintzberg, 1990; Quinn, 1978; Stacey, 1996; Wildavsky, 1979). As Mintzberg's (1987) craftsman metaphor suggests, the relation between creation and implementation of strategies is a continuous process in which the strategist, as a craftsman, gives form to the strategy by personal touch; hand and mind working together in a process of constant adaptation. So, like a handstand position (Lipski, 1978) strategy is often created by the people who implement it, sometimes at the very moment in which they implement it.

All of this serves to verify the belief that implementers inevitably have criteria and use them to interpret intended strategies in their own way (Wildavsky, 1979). Organizational members construct reality based on how they see the world, a fact that shows up in their choices, motivations and attitudes concerning performance. In this context human understanding and actions are grounded in the interpretation of information, personal experience, metaphors, puzzle solving, and the meaning ascribed to events (Daft \& Weick, 1984; Morgan, 1998; Weick, 1976, 2009).

In this context meaning is not inevitably subjective, but socially constructed by the context and intentions of the organizational actors. This principle applies to the notion of what do to, how to do it, and the actions that flow from a framework of meanings subscribed to by the members of the organization. Cognitive factors contribute to the notion that the strategic process is socialized because organizational agents are considered to have a past, interests and preferences, and that these factors affect how they make choices and act (Daft \& Weick, 1984; Mintzberg, Ahlstrand, \& Lampel, 1998; Pettigrew, 1977; Rouleau, 2005).

For Whittington (1996) strategies as a function of management are shaped by a mixture of analysis, instinct, routine, spontaneity, luck and mistakes. The competitive advantage is not a result of the strategy itself, but of the competence with which it is performed. So it is important to understand sensemaking in groups, something that inevitably involves understanding activities in terms of what people do, how they interact (Weick \& Roberts, 1993) as well as their influence on what they do.

Of equal importance are the tools and practices adopted in the strategic management of organizations. Most of the time, the process and practices adopted are not even known or evaluated by organizations. Little attention is paid to personal relationships and inter-group relationships, or political processes so important to formulating and implementing organizational strategies, especially those whose work is social. The activities and practices adopted have a significant influence on organizational results (Barley, 1986), which means good performance does not always relate to rationally prepared plans, and vice versa. The implementation of strategies may even be the result of unintentional actions or organizational practices developed to take place in parallel with the strategic plan of the organization.

A more accurate examination of the practical perspective in complex systems allows the identification of important elements of this system as well as its influence on the implementation of strategies. Elements like variability, unpredictability, instability, interactions, and repetitive causal relations constitute elements that are present in complex systems. Furthermore the presence of a great number of agents interacting, the agents' autonomy, as well as rules for the system operation, selfcoordination, cooperation and self-organization, form a unique organizational environment that characterizes complex systems. However it is people's creation and production that give meaning to complex organizations. Thus the implementation of strategy in complex systems is characterized in the research field as a unique exploratory action and in the practical field as a challenge for managers in the sense of reviewing paradigms, mental maps, beliefs and perceptions with implications for the group and individual behavior. 
Studies that consider the practical perspective have revealed strategic management specifics and how the change in complex organizations actually occurs, as Jarzabkowski (2005) stresses in her work about universities. The influence that sensemaking and organizational agents' interpretation have on the implementation of strategic changes is discussed by Rouleau (2005) in a paper that highlights the importance of middle managers. More recent studies have also associated the practical perspective to the investigation of how the order in Complex Adaptive Systems (Campbell-Hunt, 2007) is maintained, which meets the proposals of this study.

\section{Strategic Management in Complex Organizations}

Organizations have long been analyzed as complex social systems. In recent times researchers have applied theories of complexity to analyze aspects of complex organizations - how they function, what managerial practices they use and how to measure performance. One important theory is the Complex Adaptive System.

The Complex Adaptive System refers to systems wherein agents or members seek to adapt to the environment (Axelrod \& Cohen, 1999). Stacey (1996, p. 284) describes it as "a number of agents interacting with each other according to schemas, that is, rules of behavior, that require them to inspect each other's behavior and adjust their own behavior in light of the behavior of others". Thus, Complex Adaptive Systems learn and evolve by adapting and thereby surviving - by processing information and building schemas based on experience, as they move along.

Implementing strategic action becomes a serious challenge to managers of complex organizations. The process becomes more and more complex because of characteristics like unpredictability, uncertainty, and the wide variety of interactions among multiple autonomous agents.

Unlike the concept of dominance in the related literature, strategic management in complex organizations is not the result of previously established rational intentions through a formally planned process. In these organizations, non-linearity is constantly influencing decision making and developing actions. This is further reinforced when considering the limits of human rationality according to Simon (1997), by the autonomy of their members, by the intense relationships between members that have diverse interests and beliefs, and by the interdependence in the production of goods and services.

In this complex organizational context, decisions and actions are much more the result of political, structural and symbolic aspects than rational or logical ones (Bolman \& Deal, 2003; Etzioni, 1964; Pettigrew, 1977; Scott, 2008). In practice, strategy occurs interdependently - the result of cooperation and interrelationships in an environment that is neither inert nor stable, let alone predictable; which places more importance on the interpretation of reality, improvisation and creativity of organizational members (Stacey, 1996).

In complex organizations, non-linearity - illustrated by the diversity of responses to the same stimuli - obviates a shadow system, parallel to the legitimate system. In the shadow system, agents establish informal and spontaneous relationships while interacting in the legitimate system. It is precisely in this informal context that the great majority of strategies are generated and enacted in complex organizations (Stacey, 1996). Furthermore, it is from the agents' capacity of interacting, learning, and creating that strategies emerge.

Stacey (1996, p. 4) states "Together we construct in our minds the world we live in; the kind of world we construct depends critically upon the ways of thinking that we share with each other". For this reason understanding strategic practice in complex organizations requires looking into how organizational members make decisions, make sense of organizational phenomena and operate strategies. Sometimes these two roles overlap or get confused, relegating strategy to the 
implementation stage rather than the decision stage as a natural development of creativity and interaction, because thought and action are closely related.

The process of implementing strategies in Complex Adaptive Systems differs from traditional systems and theories (Axelrod \& Cohen, 1999). Organizational complexity conditions and challenges strategic management practices in these organizations. It conditions through the autonomous actors, the variety of agents, unpredictability of organizational behavior; conditioning which influences the way strategies emerge and are implemented in complex organizations. It is a challenging process because traditional models do not generally take into consideration the characteristics of complex organizations or how they demand extra effort from managers to overcome limitations - for instance the strength of the informal system.

Whether complex or traditional, the strategy execution process is determined by the participation of different strategists at various hierarchical levels (Campbell-Hunt, 2007). The consolidation and involvement of a large number of organizational agents in strategy implementation heightens the importance of observing the process from conception to operation in order to understand both how and where execution happens, as well as the practices that contribute to the process.

The introductions of practice in theory and of theory in practice are indicated by Hrebiniak and Joyce (2001) as a necessary development to better understand the transformation of intention into action. The strategic conception as a social practice underlines the strategist's role as someone who has the capacity for interacting, perceiving and making choices through a combination of intentions, interpretative efforts, intuition and subjectivity (Stacey, 1996; Whittington, 1996).

\section{Strategic management in hospitals}

Hospitals are considered one of the most complex types of organizations in modern society (Etzioni, 1964). Their complexity derives from their ambiguous aims, the qualitative nature of their activities, the use of multiple and complex technologies, shared power and the plurality of professionals that carry out activities. It is a complex system whose integrating elements are loosely coupled (Orton \& Weick, 1990; Weick, 1976). The system harbors quasi-autonomous work units or cells with weak couplings between them.

Because of these distinct characteristics, hospitals can be particularly interesting for studying strategy implementation. Similar to universities, hospitals have traditionally been observed as professional bureaucracies (Mintzberg, 1979), described as loosely coupled systems (Weick, 1976) and even organized anarchies (Cohen \& March, 1974). From this perspective, hospitals are pluralist organizations with multiple objectives not necessarily compatible with a single or global strategic direction.

In hospitals three groups with competing interests - administrators, trustees and physicians share authority, thereby constituting what Gordon (1962) called the top management triangle. Although all have power, none is effectively at the summit. Thus authority shared by administrators and medical professionals creates a conflict over scarce resources (power and authority); conflict that fuels the political environment. This tends to thwart efforts for strategic management in a hospital organization. More recently, scholars have focused on these conflicts and the problems they cause in the decision making process (Shook, Payne, \& Voges, 2005), strategy making and financial performance (Ginn, Lee, \& Ellis, 2006; Weerawardena, MacDonald, Mort, \& Gillian, 2009) and the convergence of mission and sustainability (Meyer, Pascucci, \& Murphy, 2010).

Hospitals have faced constant and significant changes resulting from rapid-paced technological advances, advances in healthcare itself, and changes in legislation. All of these improvements have pushed operational costs to record levels (Porter \& Teinsberg, 2006). These factors have also demanded more and better administration, careful planning, immediate response to external demands and corresponding attention to the expectations of the various stakeholders - altogether constituting colossal new challenges for hospitals (Bryson, 2004). The greatest challenge for hospitals is to carry 
out their social missions of providing quality health services with scant resources. To better meet these demands hospitals have begun to adopt or fortify their practices in planning and strategic management.

Some Brazilian hospitals have overcome administrative difficulties by customizing management practices to their specific needs. These organizations have learned how to reconcile the complexities inherent in hospitals with strategic management initiatives and practices, achieving positive results. One result is that administrators are learning how to implement strategies without the restriction of using purely rational tools. They are calling for new means to develop and implement strategies.

\section{Research Method}

This is a comparative, qualitative case study (Yin, 1987). The criteria that guided the selection of these cases are similarities in size and social characteristics, service performance, teaching and research, and recent professionalization and adoption of a strategic management approach. The institutions are Hospital Erasto Gaertner (HEG) and Hospital Universitário Cajuru (HUC). A further important consideration of selection was management structure-decentralized at HEG, centralized at HUC. Information like foundation, position in the health market, staff, permanent clinical staff, and number of beds, among others, is presented in Table 1 providing a profile of the hospitals focus of the study.

Table 1

\section{Profile of the Hospitals}

\begin{tabular}{lll}
\hline Characteristic & HEG & HUC \\
\hline Foundation date & 1947 & 1958 \\
Position in health market & $\begin{array}{l}\text { Renowned in oncology in the } \\
\text { South of Brazil }\end{array}$ & $\begin{array}{l}\text { Renowned in orthopedic and neurological } \\
\text { surgical treatment in Parana State }\end{array}$ \\
Type & Specialized Hospital & General Hospital \\
Beds / Clinical Staff & 1,4 / bed & 4,02 / bed \\
Staff / Clinical Staff & $8,3 / 1$ permanent & $4,3 / 1$ permanent \\
Staff / beds & 5,9 / bed & $4,02 /$ bed \\
Average attendance & 12,300 per month & 14,200 per month \\
\hline
\end{tabular}

Note. Source: Authors.

Data were gathered from September to December, 2008, from three main sources: interviews, non-participant observation, and documents. The research design selected these sources to avoid possible biases that could result from a single source of data, particularly when retrospective analysis is involved (Denzin \& Lincoln, 2000; Eisenhardt, 1989). Researchers adopted a semi-structured model of data collection composed of open-ended and standardized questions with the purpose of identifying how organizational agents act and interact when implementing adopted practices and strategies, and, especially, how these complex thought-processes coexist.

At HEG the researchers interviewed seven managers directly involved in the hospital strategic management, among them were the Superintendent, the Planning Coordinator, three senior managers and three middle managers. At HUC researchers interviewed six managers including the General Director, Chief Executive Planner, two senior managers, and two middle managers. Researchers piloted and validated the questionnaire with hospital managers who were independent of the subject hospitals. 
Interviewers audio-taped and transcribed the interviews. The transcriptions number more than 180 pages. In addition, notes taken by researchers as non-participant observers were recorded in the field diary and used in the analysis stage. On the whole the material transcribed for analysis numbered more than 200 pages. Archival materials including reports of activities, publications, and information available on websites of the hospitals were also used. Thus information gathered was based on document analysis and interpretative techniques. The variety of methods for gathering data allowed use of the Triangulation Approach (Eisenhardt, 1989; Yin, 1987) to assure the validity of the information obtained. Triangulation of data sources was sought in various types of publications, interviews, and observation strategies.

\section{Data Analysis}

In this section the characteristics of the cases are presented and analyzed with descriptions and comments about the strategic management approaches adopted. Researchers identify strategic actions of each hospital as well as formal procedures used to formulate strategies, allocate resources, monitor and control. Researchers examine the level of unfolding and interaction between agents in taking charge of strategies and how this process contributed to the implementation of strategy in either case.

\section{Case 1: hospital Erasto Gaertner (HEG)}

Hospital Erasto Gaertner is a premier center of oncologic treatment in the southern region of Brazil; it is nationally and internationally renowned in cancer treatment and research. The hospital is also a teaching hospital and center of oncologic research.

With the intent of improving organizational performance, in 2002 HEG adopted strategic management techniques and implemented or acquired quality certification and hospital accreditation. During this period administrators initiated programs to improve the professional skills of management and staff. Administration developed long-term strategic goals of achieving financial independence, consolidating its national image as a renowned hospital in oncological treatment, enhancing or professionalizing the image of staff, and attracting more patients from the private health care system (those whose insurance would cover full costs of healthcare).

Strategic management. Strategic management at HEG engages top administration, middle management and operation-level employees - with appropriate variations in intensity. Administrators established the Planning Group assigning it the duty of elaborating and following up the HEG Annual Plan of Work (APW) that comprises the main objectives and practical actions for achieving the strategic goals of the hospital, as well as monitoring and controlling the implementation of strategies. Implementation results are strategic guidelines and actions that emerge from the decisions of the administration (directed to where to go), based on rational analysis and summarized in the Annual Plan of Work. Similarly, strategies that emerge from the actions of managers (directed to how to do) are heavily influenced by psychological aspects. They are the interpretations of reality, experiences and insights; all of which are responses to change flowing from the strategies as planned.

Researchers further observed interaction continues through meetings when middle managers, who operate closer to operations, work to identify strategies to solve weaknesses. They also noticed during field observations that plans are flexible - managers make adjustments constantly by including, excluding, or substituting strategic actions directly in response to unpredictable internal and external factors. Every week administrators conduct follow-up meetings with middle managers to discuss and rank priorities. According to one informant, "people need to know exactly what has to be done". The hospital schedule of meetings takes on a character similar to what Axelrod and Cohen (1999) call interaction patterns, where each group develops a specific interaction dynamic with codes, events, and routines known and understood by all members. This second source of strategy demonstrates that 
the plan is flexible and is constantly adjusted for inclusion, exclusion, or change of actions (known as the influence of unpredictability).

Even with possible limitations because of inspection by regulators, technological development, scarcity of resources and conflict between the shadow system and the legitimized system, the hospital demonstrates it is unwilling to stray from its long-term strategic goals. The permanent adjustments of APW demonstrate that the hospital has learned to deal with unpredictability. The how to is constantly in flux - not the what to as defined earlier. In this kind of strategic practice results come more slowly because the hospital is highly complex and diverse.

Researchers observed that middle managers participated in creative activities as described by Stacey (1996) and Rouleau (2005). These managers took part in meetings where possibilities, priorities and feasibility of suggested actions were freely discussed. One informant stated that "the follow-up of the work and objectives accomplished during the month is done with the right person, at the operational level". Therefore it is with the collaboration of the practitioners' vision that strategic actions are reviewed. Meetings of this type demonstrate the motivation and efforts to integrate managers, leaders and opinion shapers. Equally important is the loose coupling among some internal groups - especially technical professionals - where autonomy is common. In this way the hospital worked to integrate the legitimized system with the shadow system and to coordinate individuals with sectors.

Researchers identified a gap between goals, strategies that were internally mandated and externally communicated to stakeholders, and emerging objectives or strategies flowing from organizational dynamics - informal activities leading to effective implementation. This phenomenon illustrates a symbolic frame of reference in strategic management as well as the organization's capacity to regulate itself and adjust to the environment. To managers this gap is justified by the complex nature of the organization that demands diversified, flexible and effective management practices. One informant reported that "the establishment of a process of strategic planning in the health system is painful because the system itself, health plans or public health care, undergoes almost constant change". Strategic management has effectively assisted the organization to become more proactive and less reactive.

Implementation of strategies. Hospital management worked hard to resolve conflicts of interest and to teach managers to live with unpredictability. The implementation of strategies in the hospital illustrates a political rationality or framework in organizations, as noted by Pettigrew (1977) and Bolman and Deal (2003).

Management attempted to manipulate the groups to minimize resistance and engage them in the change process - especially leaders and opinion makers. Management negotiated with the groups throughout plan preparation and implementation. One informant noted that rather than working with all collaborators, they worked with "fifty, sixty people that spread the organizational culture, planning and quality to the rest of the organization". Administrators created specific managerial positions so clinical staff could be cared for by managers with medical training.

Hospital management clearly and transparently presented formal plans and goals so they could be easily communicated and understood by organizational members and other stakeholders. These tactics are consistent with Chaffee's interpretive model (1985). Her model addresses the social construction of reality; emphasizing the political, procedural and psychological nature of the strategy. In this model people interpret strategies based on their beliefs, interests, and world view and act as a result of their interpretation. Furthermore, management demonstrates strategic actions, objectives, and performance indicators to members of the organization. In these meetings management discusses difficulties and achievements, then further analyze the need for additional actions to achieve objectives. These reviews provide an opportunity for analysis and review of the issues that emerge from the implementation of strategic actions. Stacey (1996) suggests these actions constitute the exercise of self-control as an inherent characteristic of complex systems. 
Management often uses specific practices in the implementation of strategies involving various agents and hierarchical levels. In this scenario, management is decentralized inasmuch as interaction among those involved, and praxis - activities people do in practice - is developed from the practitioner's sensemaking (to use Weick's term). One informant reported that "personal experiences are taken into consideration, the person's expertise. This is applied to the execution of the plan of actions, annual plan of work among others. In conclusion, you use personal experience in everything" (interview).

One can observe that the practices and praxis adopted by the hospital in implementing its strategies tends to decrease complexity in the execution of strategy. Five categories defined from the elements of complexity (Axelrod \& Cohen, 1999; Stacey, 1996) are used to classify practice and praxis of the hospital's implementation strategies.

Table 2

Practices and Praxis used at HEG in the Implementation of Strategies

\begin{tabular}{|c|c|c|}
\hline Category & Practices & Praxis \\
\hline \multirow{2}{*}{ Autonomy } & $\begin{array}{l}\text { Total freedom of performance at several } \\
\text { levels }\end{array}$ & $\begin{array}{l}\text { Participation of the clinical staff on } \\
\text { decisions }\end{array}$ \\
\hline & $\begin{array}{l}\text { Forums for the discussion of conflicting } \\
\text { subjects }\end{array}$ & Being flexible and looking for dialogue \\
\hline Shadow system & Opinion leaders & $\begin{array}{l}\text { Actions based on "listening, analyzing and } \\
\text { acting" }\end{array}$ \\
\hline \multirow{2}{*}{ Interaction } & \multirow{2}{*}{$\begin{array}{l}\text { Systematic meetings that reinforce the } \\
\text { interaction patterns }\end{array}$} & Intense among practitioners \\
\hline & & Participation at different hierarchical levels \\
\hline \multirow[t]{2}{*}{ Control } & $\begin{array}{l}\text { Systematic review of actions } \\
\text { objectives }\end{array}$ & Persistence with the method of guidance \\
\hline & Performance indicators & Unfolding at all levels and activities \\
\hline Self-organization & Incentives to creativity & Informality in the exchange of information \\
\hline
\end{tabular}

Note. Source: Authors.

Group autonomy is a strong characteristic of complex organizations, such as hospitals or universities, where professionals like doctors or professors make up the labor force. This case shows that hospital management has received the support of autonomous groups by sharing responsibilities and demonstrating trust. One interviewee emphasized the search for balance between "knowing what to expect from people and at the same time not letting them so free to do whatever they wish" (interview). One effort to better integrate the several professional areas was the Human Resources Department's The Week of Physician: forums that gathered experts from a variety of related fields to discuss administrative issues within the Hospital. One event was especially effective: the presentation by the conductor of a symphony orchestra who explained the role of each instrument and the need to integrate them in order to have a symphony. The metaphor was immediately clear to the audience.

Maintaining dialogue above everything is a praxis that produced good results in integrating efforts between the shadow system and the legitimate system. The work of opinion leaders as members of groups comprising the organization created the belief that "if someone is against something, it is because at least an analysis of what is being said is needed" (interview). Upper management staged interactions between groups both vertically and horizontally in the hospital, reinforcing what Axelrod and Cohen (1999) suggested when they referred to interaction patterns. These patterns, developed by organizational agents, are important to the process of strategic management. Management communicated not only that they will be heard, but that they will also be accountable. 
When plans, actions and objectives are systematized, organizational members accept their responsibilities and contribute to the process. At the same time many would criticize the rationality of systemizing. The hospital lives with unpredictability, uncertainty, a variety of interactions; the stakes are raised because its major service focus is life itself. Training and legitimated practices, such as Total Quality Management and the Hospital Accreditation Program, have helped make the process understood as a necessary condition for the adoption of new procedures and, consequently, for the construction of a new culture focused on results. The new pattern is necessary for sustainability.

\section{Case 2: hospital Universitário Cajuru (HUC)}

Hospital Universitário Cajuru (HUC), in Curitiba, Brazil, is renowned for its clinical service as well as orthopedic and neurological surgery. As a trauma center, it is considered the major provider of trauma emergency care in the state of Parana. HUC is accredited by the Brazilian Ministry of Health as a high complexity hospital in orthopedics, trauma and renal transplant. HUC is also a teaching hospital associated with a large Brazilian university. It launched the first master degree in trauma surgery in country. HUC is a member of an alliance with three hospitals in the city of Curitiba. It has more than 1,000 beds and is managed by a holding company.

In 2006, HUC began a restructuring process of professionalizing management - an effort that concluded in 2008. Integral to bringing about organization change was the adoption of strategic management during the time of professionalization. The strategic management plan included some of the organization's medium-term strategic goals, such as: changing the service mix by increasing services to patients in the private health care system; the pursuit of self-sustainability through reduction of operational costs; establishment of a reputation as a renowned health center; improving quality of service; and creating new mechanisms for feedback and learning.

Strategic management. Because HUC is only one of the holding company's businesses, its strategic management efforts become a target for the holding company's leadership to exert strong influence and control. The holding company's board of directors makes most of the important decisions and issue directives for hospital units to follow, thereby integrating the company network. HUC has its own executive board of directors, intent on executing goals and strategies as defined by the holding company. From 2006 on, following the strategic plan of the holding company, a mediumterm plan for the hospital emerged: composed of strategic goals, objectives and actions. Every year, during a review of the holding company's plan, the objectives, goals and actions sought by the hospital are also reviewed. This process creates the annual plan of action, including a budget, all arranged through a standard, rational process.

Strategic management techniques are evident both inside and outside the organization in instances of decision making and follow-up. The Administration Council, Executive Committee of the Health Area, and the Health Alliance conduct weekly meetings where the board of directors presents the current status of the strategies. Meetings with the hospital staff's senior team occur weekly as well. Only recently have presentations of strategic actions and objectives been made to middle management. Even though interactions are constant, the pattern of interaction, as stated by Axelrod and Cohen (1999), is situated at the executive level, never quite reaching the operational level. One interviewee noted "the redesign of the organizational model" that had its start in 2006 faced difficulties in its implementation. The same interviewee added that these difficulties "are even more present in the health area due to the involvement of the medical staff. We see, here, great resistance of these various factors in implementation" (interview).

Accordingly, at HUC the defined goals and actions were rarely changed or adjusted. Nevertheless the hospital is vulnerable to environmental challenges and unpredictability, like all complex organizations. These are new demands confronting organizational management in its capacity of adapting to internal changes in defining new priorities and reallocating resources. HUC finds itself pressured to change previously established objectives and actions. 
HUC's holding company engages with the external environment: federal legislation, governmental resources, shifts in the economy and health plans. Beyond the scope of the hospital, the board of the holding company interacts with stakeholders, governmental agencies, regulating agencies and society in general.

This case confirms the existence of, and serves as an excellent example of, a loose coupling relationship between internal and external groups. It is this professional bureaucracy, as stated by Mintzberg (1987) that showcases professionals as physicians and nurses who have autonomy and control over their own work. They work directly with patients, independent of colleagues. This is especially true, perhaps, because HUC is a teaching hospital.

Physician professors are well respected and enjoy great autonomy. Their reputation tends to strengthen the already-strong shadow system present in the hospital, as described by Stacey (1996). It also jeopardizes implementation of changes needed to unearth established objectives and strategies. About the physician professors, an interviewee emphasized that "it is not easy to standardize, it is not easy to introduce protocols of assistance. The procedures are strongly influenced by the autonomy of professionals" (interview). This statement suggests that the shadow system (Axelrod \& Cohen, 1999; Stacey, 1996) and the legitimated system are interventions developed by management, even if unsuccessful.

Adoption of the strategic management approach indicates the need for management professionalization and for a management information system to inform decisions, actions and control at the hospital. The hospital board of directors developed training and qualification programs for middle managers and designed a managerial information system (MIS). The MIS defines a hundred indicators of feedback from systems considered fundamental for strategic control, especially reviewing or measuring strategic objectives, actions and managerial processes. One interviewee stressed the importance of this change for strategic management when he stated that "in the past years there has been a total lack of quantitative information so that we could promote the change of an amateur management for a management centered on information system" (interview). Some observers saw senior management responsible for strategy had tried to get closer to operations, even though middle managers' participation in 2008 fell short.

Implementation of strategies. The implementation of strategies at the hospital occurred in two phases. The first was a review of internal processes that support and qualify middle managers for work directed to strategic management. The second was dedicated to solving conflicts of interest among stakeholders of the strategic process. Political rationality, as stated by Pettigrew (1977) and Bolman and Deal (2003), is also present in the majority of the hospital initiatives flowing from the holding company's administration as well as from hospital management. They attempted to weaken the shadow system and deal with the loose coupling among the groups in senior management and in operations.

Because the holding company focused on decision making and setting hospital goals and strategies, strategic management practices were curtailed, especially because middle managers did not understand where and how to implement strategies. This made the work of agents directly responsible for operations more difficult. As implementation became more centralized, one interviewee acknowledged that strategic management is effective only when "it is popular, democratic and clear for the whole staff of the institution" (interview). For the same interviewee, strategic actions require interaction and broadcasting among participants because individuals must have "awareness at least for their field of performance, of what is expected from his/her professional performance, which are the great objectives of the area so that he/she can have a vision of the whole and how he influences the global results of the unit" (interview).

This perception shows that participation is key to achieving better results in implementing strategies. An interviewee stressed this when he said the expectation is that in 2009 the "strategic decisions of the strategic planning and of the main guidelines include the functional and technical staff' (authors' emphasis). This testimony stresses the importance of participation by the operational 
agents, as middle managers mentioned. Participation reinforces the practical perspective of the strategy and the interaction present in the theory of Complex Adaptive Systems. It had been the holding company that established, broadcasted and guided the implementation of rules, internal controls, performance indicators and other management tools to improve processes affecting strategic practices.

The process of centralization at HUC channeled efforts and practices to implement strategies at the political and structural domains. This is because of actions taken by the holding company. It considerably reduced the hospital's autonomy and reduced the involvement of lower levels of management in the strategic process. As at HEG, five categories were adopted, as defined from the elements of complexity (Axelrod \& Cohen, 1999; Stacey, 1996) to classify the practices and praxis adopted by HUC to implement strategies.

Table 3

Practices and Praxis Used by HUC in the Implementation of Strategies

\begin{tabular}{|c|c|c|}
\hline Category & Practices & Praxis \\
\hline Autonomy & $\begin{array}{l}\text { Strict and top-down strategic } \\
\text { programming }\end{array}$ & $\begin{array}{l}\text { Performance freedom as group interests and } \\
\text { professional prestige are observed }\end{array}$ \\
\hline Shadow system & $\begin{array}{l}\text { Use of personal prestige to make } \\
\text { things happen }\end{array}$ & $\begin{array}{l}\text { Power practice by professional groups } \\
\text { (professional bureaucracy) }\end{array}$ \\
\hline & Strong vertical interaction & Practice of political rationality \\
\hline Interaction & Frequent inside each area/group & $\begin{array}{l}\text { Informal discussions in working environment } \\
\text { and outside }\end{array}$ \\
\hline \multirow{2}{*}{ Control } & $\begin{array}{l}\text { Systematic meetings of the high } \\
\text { management }\end{array}$ & Outside the organization (Holding Group) \\
\hline & Information managerial systems & $\begin{array}{l}\text { Accomplishment of the strategic program and } \\
\text { system feeding }\end{array}$ \\
\hline Self-organization & $\begin{array}{l}\text { Strong external control (Holding } \\
\text { Group) }\end{array}$ & $\begin{array}{l}\text { Power practice by the one who has the power } \\
\text { and accomplishment by the others }\end{array}$ \\
\hline
\end{tabular}

Note. Source: Authors.

While the autonomy of the hospital was limited by the holding company in the strategic process, some groups found greater autonomy - specifically technical professionals - thereby hindering the implementation of strategies even more. The few strategies implemented resulted from negotiations between the legitimated system and a strong shadow system.

Complexity, autonomy and a shadow system complicate organizational interactions, especially when units differ as much as technical and administrative ones. However analysis indicates intense interaction inside each professional group, both formally and informally. Upper management, on the other hand, experiences better interaction with the boards of directors of both the holding company and of the hospital - it happens formally with systematic meetings. Norms, rules and internal policies are adopted as practices contributing to strategies are implemented at various levels of the organization.

The development of the managerial information system by upper management contributed to evaluation of performance based on a group of indicators linking decision making, execution and control. Senior administration believed transparency and making information available through the management information system positively reduced resistance at intermediate and operational levels regarding setting objectives and initiating action. This practice, as well as Process Review, Hospital Accreditation and Risk Management, are parts of the larger efforts undertaken by hospital 
management to garner support of mid-level managers and operational agents and to weaken the strong shadow system at HUC in order to increase the effectiveness of strategy implementation.

\section{Discussion section}

To identify practitioners of strategy was primary to the study. The identification of strategizing practices as adopted by organizations accounted for different processes and strategic management results at the two hospitals. The study focused on the experience of the two distinguished hospitals that serve as national benchmarks - standards of excellence - in their fields.

Four research questions guided this study: (a) How is the work of strategizing done?; (b) What practices are developed related to the implementation of strategies?; (c) Who does the work of strategizing?; and, finally, (d) What do the hospitals share in common and how do they diverge in the implementation of strategies? To answer these questions, the strategic process was examined, including practices, praxis and practitioners in the context of two hospitals.

Strategizing was different for the two hospitals. At HEG the practitioners were middle managers who made things happen. They had the support of employees at the operational level. At HUC strategizing was quite different. Because of tight control by the holding company, the number of strategic practitioners was seriously reduced. Strategizing was concentrated in staff operating at the upper level of administration. The paucity of information available restricted the contributions of middle-managers and lower levels in the implementation process. This situation reinforced the existence of a loosely coupled system in the hospital.

Strategizing at HEG was characterized by strong participation and transparency of the process. Intense interaction was formally and informally encouraged by managers at all levels to stimulate the exchange of ideas and experiences. The planning coordinator assigned responsibility for the process to middle and operational managers. It was up to them to think, choose and implement strategic and operational actions, as described by Stacey (1996).

Even though few incentives were available to motivate practitioners to achieve strategic goals, there was punishment for those who failed to achieve planned goals - budget cuts for the unit, for instance. The praxis making a large contribution toward the implementation of strategies were the meetings wherein face-to-face interaction occurred, involving practitioners taking action. The general director of the hospital provided guidance, trust and motivation, thereby empowering every group of professional, at all levels, to strategize independently and in concert with each other.

Strategizing at HUC is yet to reach the hospital's operational level. Strategy implementation has a strong political ingredient because of the competition for scarce financial resources controlled by the holding group. Strategizing, therefore, takes place mainly at the senior administration level and also between the hospital and the holding group. Strategies are planned by the chief executive planner of the holding company, and then transferred to upper administration, with performance indicators attached.

Data analysis of strategy implementation revealed practices at HEG like the strategic plan, budget, Total Quality Management (TQM), Balanced Scorecard, and Hospital Accreditation Program. Other practices were developed such as programmed meetings involving top administration, middle management and the operations level. HEG used a systematic review of strategic actions to cope with environmental factors, internal changes, uncertainties and adjustments to align actions and objectives.

Practices at the Hospital Universitário Cajuru (HUC) were also concentrated on the strategic plan, budget, Balanced Scorecard, and Hospital Accreditation Program. HUC also implemented Risk Taking Management to mitigate risks related to internal processes and operations. Weekly meetings contributed to the improvement of the implementation of strategies. Compared to HEG, HUC meetings included only representatives of the holding company and senior administration. 
Planned strategies and actions do not filter intact down the hierarchy strategies, but rather as policies, rules, and protocols for actions. The responsibility of middle and lower level managers is to follow the general guidance from the top without room for interpretation or improvisation. The outcome of this centralized management is that those who decide what to do are not at all involved with implementing the strategies and those in charge of implementing the strategies are unaware of the overarching goals and objectives of the hospital. HUC may more aptly be called an organized anarchy than a strategically-managed hospital.

This analysis indicates that HUC's top administration understands that one pitfall of the strategic management process squarely resides in the implementation stage, not in the formulation stage, of strategy making. Another factor affecting process effectiveness is classic resistance to change by groups such as the health professionals and technicians. The severe consequence here is the gap of interaction between those at the top of the hierarchy and those in the middle and lower levels responsible for execution. The study indicated that strategic management takes on strong symbolic meaning. In fact planning itself provides status and an image of sophistication for management - both relevant in relating to stakeholders.

The only strategies implemented are those directly carried out by senior management; they deal with the relationships with external stakeholders - the real action according to Stacey (1996). The adoption of strategic management, managerial professionalism, and process review are initiatives to improve performance. Clearly the strategic management approach in effect is effective and contributes mission fulfillment.

These findings indicate that everyday practices are adopted in parallel with the formal planning system and yet they are characterized by informality. The strategic practices contribute significantly to the self-organization of the management system and encourage the alignment of initiatives and actors with the mission of the hospital. Almost all the practices occur informally, in what Stacey (1996) termed the Shadow System. The implementation of strategies in the hospitals resulted in practices and interrelations that were political in nature. Politics was a key factor for success, implying that, in practice, many strategies are not the result of formal plans but rather more political and symbolic than rational.

Analysis further revealed different practices and performances, leading to the conclusion that the implementation effectiveness in complex organizations like hospitals has to do with the practices and processes that are adopted (how) and the practitioners (strategists) involved (who). Analysis also showed that practitioners of strategy occupy many positions up and down the organizational hierarchy. Most often they are not members of top management or the group of directors in charge of corporate strategies. Strategy is the work of middle management. This finding reinforces the importance of understanding the strategizing process and the role it plays in the implementation of strategies. When done well, the successful process spreads to other organizations with similar characteristics.

Similarities in the cases are significant, especially in the practices employed. The distinction between practices and praxis helps explain the differences in the results found in the implementation of strategies at both hospitals. Execution of strategies derives from well-defined configurations. In both cases the influence of complex systems can be observed.

HEG tends to be more loosely coupled as a system fostering greater autonomy for agents, more capacity for self-organization and a more flexible control system - implying a weaker shadow system. At HEG, because of greater decentralization and flexibility, agents had more autonomy, thereby stimulating strategizing and enhancing the practice of sensemaking and creativity. At the same time it valued the expertise of professionals. The complexity of these practices is illustrated in Table 4. 
Table 4

\section{Comparison of the Implementation of Strategies between Hospitals}

\begin{tabular}{lll}
\hline Category & HEG & HUC \\
\hline Autonomy & Balanced and not harmful & $\begin{array}{l}\text { Specific professional groups creating } \\
\text { conflicting relationships }\end{array}$ \\
Shadow system & Existing and powerless & Strong, resistant and influential \\
Interaction & Intense, pro-active and influencing results & Vertical pattern, limited and a bit ineffective \\
Control & Systematic and flexible & Systematic and strict \\
Self-organization & Incentive to adaptation and creativity & Limited space for adaptation and change \\
\hline
\end{tabular}

Note. Source: Authors.

Some actions are perceived as strategies after execution. In this regard, Mintzberg and Waters (1985) pointed out that even when coherence could be identified, strategic actions are identified as retrospective rationality. In this case emergent strategies are integrated as part of management and linked afterwards to organizational plans. At HUC, strategic management was driven through a centralized system by top management with great bureaucratic rigidity, exhibiting a strong presence of the shadow system. This reduced autonomy for agents and because interactions occurred through more formal channels, thinking and acting strategically (strategizing) was greatly reduced. Sensemaking did not emerge and consequently was not absorbed into the practice of strategy.

Strategy and its practice, as a mental and interpretative process, cannot be an end in itself, limiting the vision of practitioners to elements surrounding the action and organizational context. Mintzberg (1987) warns of the risk of strategies becoming a visor on the agents' head that obstructs the peripheral vision crucial for process development.

\section{Conclusions}

To manage complex organizations, such hospitals, is a modern day challenge of the greatest proportion. The complexity of hospitals, like the nature of their services, is complicated by organizational structure, professionals and their autonomy, interactions among agents, power of interest groups and internal politics, and vulnerability to the external environment. All of these factors strongly influence managerial practices and performance.

Strategic management of complex systems, like hospitals, requires more-than-usual attention by managers of the strategy implementation process and its complexity. Managerial approaches imported from the business sector, based on rational models, are simplistic; they do not work in complex environments like hospitals. If attention is not paid to the complexities of the hospital, managers will risk destabilizing their organization and reducing its performance.

Even though the hospitals have made some progress lately in professionalizing their management teams (as represented by the growing number of experienced managers), management still struggles to be fully professional. Most managers lack the professional preparation and vision necessary for the job. Others from industry fail to take into consideration the unique characteristics and complexity of hospitals.

The lack of appropriate theories and managerial practices that consider the specificities of hospitals as organizations is appalling. Worse, Hrebiniak (2005) reminds us that managers are prepared to plan, but not to implement strategies. Lessons from these Brazilian cases confirm the 
conclusion that strategy as social practice is critical, not only for a better understanding of the implementation of strategies but also for its influence on management effectiveness. Intentionally or retrospectively, praxis used by hospitals mold formal and informal strategic managerial approaches into the complex characteristics of these organizations.

Strategic practices do not explain everything. Other variables, like political and cultural factors, affect managerial practices. Strategists must also take into account the volatile and unpredictable environmental forces. Complexity is present in hospitals; it shapes the way managerial approaches are identified, adopted and implemented. In these days of global uncertainty, instability and competition, the search for a better understanding of how strategies are executed and provide meaningful results is the sine qua non for leaders who hope to bring about success in any organization.

\section{Received 30 August 2010; received in revised form 17 December 2010.}

\section{Acknowledgements}

The authors are especially grateful to Joe McCann and Woods Bowman for their insights and important comments on the original version of the paper. The final responsibility, however, remains with the authors.

\section{References}

Axelrod, R., \& Cohen, M. D. (1999). Harnessing complexity: organizational implications of a scientific frontier. New York: The Free Press.

Barley, S. R. (1986). Technology as an occasion for structuring: evidence from observations of CT scanners and the social order of radiology departments. Administrative Science Quarterly, 31(1), 78-108.

Bolman, L. G., \& Deal, T. (2003). Reframing organizations. San Francisco: Jossey-Bass.

Bryson, J. M. (2004). Strategic planning for public and nonprofit organizations. San Francisco: Jossey-Bass.

Campbell-Hunt, C. (2007). Complexity in practice. Human Relations, 60(5), 793-823. doi: $10.1177 / 0018726707079202$

Chaffee, E. E. (1985). Three models of strategy. Academy of Management Review, 10(1), 89-98.

Cohen, M., \& March, J. (1974). Leadership and ambiguity. New York: Mc Graw-Hill.

Daft, R., \& Weick, K. (1984). Toward a model of organizations as interpretation systems. Academy of Management Review, 9(2), 284-295.

Denzin, N. K., \& Lincoln, Y. S. (2000). Introduction - entering the field of qualitative research. In N. K. Denzin \& Y. S. Lincoln (Eds.), Handbook of qualitative research (pp. 01-28). Thousand Oaks: Sage.

Eisenhardt, K. M. (1989). Building theories from case study research. Academy of Management Review, 14(4), 532-550. doi: 10.2307/258557

Etzioni, A. (1964). Modern organizations. New Jersey: Prentice-Hal. 
Ginn, G. O., Lee, R., \& Ellis, T. (2006). Community orientation, strategic flexibility and financial performance in hospitals. Journal of Healthcare Management, 51(2), 111-122.

Gordon, P. J. (1962). The top management triangle in voluntary hospitals (II). The Journal of the Academy of Management, 5(1), 66-75.

Hrebiniak, L. G. (2005). Making strategy work: leading effective execution and change. Upper Saddle River: Wharton School Publishing.

Hrebiniak, L. G., \& Joyce, W. (2001). Implementing strategy: an appraisal and agenda for future research. In M. A. Hitt, R. E. Freeman, \& J. S. Harrison (Eds.), The blackwell handbook of strategic management (pp. 602-626). Oxford: Blackwell Publishers Ltd.

Jarzabkowski, P. (2005). Strategy as practice: an activity-based approach. London:Sage.

Johnson, G., Melin, L., \& Whittington, R. (2003). Guest editors' introduction: micro strategy and strategizing: towards an activity-based view. Journal of Management Studies, 40(1), 3-22. doi: 10.1111/1467-6486.t01-2-00002

Johnson, G., Scholes, K., \& Whittington, R. (2007). Explorando a estratégia corporativa: texto e casos. Porto Alegre: Bookman.

Lipski, M. (1978). Standing the study of public policy implementation on its head. In W. D. Burnham \& M. W. Weinberg (Eds.), American politics and public policy (pp. 391-402). Cambridge, MA: MIT Press.

Meyer, V., Jr., Pascucci, L. M., \& Murphy, J. P. (2010, July). Strategies in Brazilian nonprofit hospitals: convergence of the social mission and sustainability. Proceedings of International Conference of the International Society for Third Sector Research (ISTR), Istanbul, Turkey, 9.

Mintzberg, H. (1979). The structuring of organization. Englewood Cliffs, NJ: Prentice Hall.

Mintzberg, H. (1987). Crafting strategy. Harvard Business Review, 65(4), 66-77.

Mintzberg, H. (1990). Does decision get in the way? Organization Studies, 11(1), 1-5.

Mintzberg, H. (1994). The rise and fall of strategic planning: reconceiving roles for planning, plans, planners. New York: The Free Press.

Mintzberg, H., Ahlstrand, B., \& Lampel, J. (1998). Strategy Safari: a guided tour through the wilds of strategic management. New York: The Free Press.

Mintzberg, H., \& Waters, J. A. (1985). Of strategies, deliberate and emergent. Strategic Management Journal, 6(3), 257-272. doi: 10.1002/smj.4250060306

Morgan, G. (1998). Images of organization. Newbury Park: Sage.

Murphy, J. P. (2007). Tensões entre a missão e o empreendimento institucional: obstáculos à criatividade. In J. P. Murphy \& V. Meyer Jr. (Orgs.), Liderança e gestão da educação superior Católica nas Américas (pp. 19-42). Curitiba: Editora Champagnat.

Orton, J. D., \& Weick, K. E. (1990). Loosely coupled systems: a reconceptualization. The Academy of Management Review, 15(2), 203-223. doi: 10.2307/258154

Perrow, C. (1986). Complex organizations: a critical essay (3rd ed.). New York: McGraw-Hill.

Pettigrew, A. M. (1977). Strategy formulation as a political process. International Studies of Management and Organization, 17(2), 78-87. 
Pfeffer, J., \& Sutton, R. I. (2006). Hard facts, dangerous half-truths and total nonsense: profiting from evidence-based management. Massachusetts: Harvard Business Press.

Porter, M., \& Teinsberg, E. O. (2006). Redefining healthcare: creating value-based competition on results. Boston: Harvard Business School Press.

Quinn, J. B. (1978). Strategic change: 'logical incrementalism'. Sloan Management Review, 20(1) 721.

Rouleau, L. (2005). Micro-practices of strategic sensemaking and sensegiving: how middle managers interpret and sell change every day. Journal of Management Studies, 42(7), 1413-1441. doi: 10.1111/j.1467-6486.2005.00549.x

Scott, W. R. (2008). Institutions and organizations: ideas and interests (3rd ed.). Los Angeles: Sage.

Shook, C. L., Payne, G. T., \& Voges, K. E. (2005). The "what" in top management group conflict: the effects of organizational issue interpretation on conflict among hospital decision makers. Journal of Managerial Issues, 17(2), 162-177.

Simon, H. (1997). Administrative behavior (4th ed.). New York: The Free Press.

Stacey, R. D. (1996). Complexity and creativity in organizations. San Francisco: Berret-Koehler.

Weerawardena, J., McDonald, R. E., \& Mort, G. S. (2009). Sustainability of nonprofit organizations: an empirical investigation. Journal of World Business, 45(4), 346-356. doi: 10.1016/j.jwb.2009.08.004

Weick, K. E. (1976). Educational organizations as loosely coupled systems. Administrative Science Quarterly, 21(1), 1-19. doi: 10.2307/2391875

Weick, K. E. (1979). The social psychology of organizing. New York: Tandom House.

Weick, K. E. (2009). Making sense of organization: the impermanent organization. Chichester: John Wiley \& Sons.

Weick, K. E., \& Roberts, K. H. (1993). Collective mind in organizations: heedful interrelating on flight decks. Administrative Science Quarterly, 38(3), 357-381.

Whittington, R. (1996). Strategy as practice. Long Range Planning, 29(5), 731-735. doi: 10.1016/0024-6301(96)00068-4

Wildavsky, A. (1979). Speaking truth to power: the art and craft of policy analysis. Toronto: Little, Brown and Co.

Yin, R. (1987). Case study research: design and methods. Beverly Hills: Sage Publications. 